\title{
EFFECTS OF ID-540 ON AVERAGED PHOTOPALPEBRAL REFLEX IN MAN
}

\author{
Masiltoshi TANAKA, Hiroshi ISOZAKI* and Kazutoyo INANAGA** \\ Department of Phamacoleys and Lustitute of Brain Disedses, \\ *Dopatmont of Comtral Clirical Laboratory and * Department of" \\ Reuropschiany and haswine of Brain Diseases, Kanme University \\ School of Medicine, Karme 830 , Japan
}

Accepted April 6, 1977

\begin{abstract}
Effiets of [D-540, a recenty intredtued benzodiazepine derivative, on the averaged photopalpebral reflex (PPR), subjective symptoms and serum levels of [D-540 and its principal metabolite, $N$-desmethyl-ID-540 following an oral dose of $0.5 \mathrm{mg}$

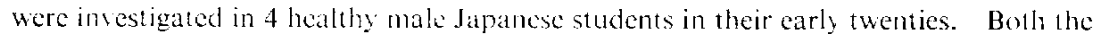
latencies of PPR, $P_{1}$ and $P_{2}$ latchey, showed a prolongation and maximum level at 2-2.5 hours after administration and lended to decline thereafter to control levels. The serum concentration of ID-540 showed a peak level at 2 hours after dosing, then showed a decline at 4 horirs. The N-desmethyl-ID-540 exhibited a slow, gradual rise in the serum oser the first 4 hours and there was a tendency toward a continued rise even at 24 hours. These parameters were of striking resemblance in the timc-course of changes after oral doming. Thus the PPR test may be a useful means of determining the clinical effects of anxiolytic anents. II)-540 apnears to be an agene with remarkable anxiolytic effects.
\end{abstract}

Determining the clinical effects of drugs from pharmacological findings obtained in laboratory animals and from data in normal subjects is a matter of prime importance, yet considerable difficulties are involved in such an attempt $(6,7)$. There is a great need for development of practical sflicient measures of estimating clinical efficacies of newly introduced medicaments. The quantitative pharmaco-electroencephalography described by Itil (3) appears to be a useftil method for the determination of clinical effects of psychotropic agents.

In previous papers, we predicted the clinical efiects of some anxiolytic drugs by analysis of changes in averaged pholopalpebral reflex (PPR) observed in healthy human adults (4, 8 ,9). The PPR is a record of the mean of summated reflexive contrations of the orbicularis oculi muscle to periodically applied photic stimuli and shows changes in sensitive responses to pain stimuli (5) and to changes of the level of consciousness, etc $(2,5,10)$. Previous studies with conventional anxiolytic drugs also demonstrated its usefulness as a clinicopharmacological lest $(8,9)$.

These previous investigations were primarily aimed at comparative assessments of PPR and subjective changes, and in the present work, more detailed studies were done to ascertain the practical applicability of the PPR test. 


\section{MATERIALS AND METHODS}

Drug

ID-540, the chemical structure of which is 7-chloro-5-(2-fluorophenyl)-1methyl-1 H, 4-benzodiazepin-2 (3H) 0 one, is a derivative of benzodiazepine and is shown in Fig. 1.

The drug has profound anticonvulsant activity, taming effects, muscle relaxant effect and potentiates the effects of hexobarbital and chlorprothixene (1).
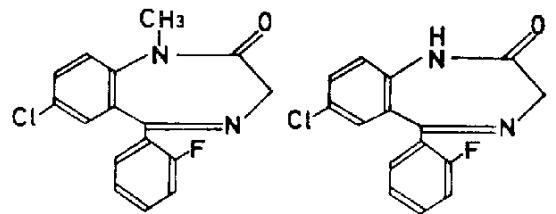

ID-540

N-Desme thyl-1D-540

Гio. 1. Chemical structures of ID-540 and its $\mathrm{N}$-demethylated metabolite, N-desmethyl-ID-540.

Clinically this drug may be prescribed for relief of anxiety, tension and irritability and symptoms of muscular stritin. Drowsiness and a feeling of weakness may appear as side effects of the drug.

\section{Test procedure}

Four male Japanese students aged 23 to 27 ycars who were assessed to be physically and mentally healthy served as volunteers.

The estimated dose of the drug was determined according to the data of animal studies (1) and a phase I study in human beings (Ogawa, N., unpublished observation).

After recording the control PPR at 1:00 p.m., $0.5 \mathrm{mg}$ ID-540 (capsule) was orally administered. The PPR tracing was then repeated $0.5,1,1.5,2,2.5,3,3.5$ and 4 hours after medication. A $5 \mathrm{ml}$ sample of blood was drawn from the median cubital vein of each volunteer by means of vacuum blood collection tubes prior to and 1, 2, 4 and 24 hours after drug administration and assays were done on ID-540 and its N-demethylated metabolite.

Each subject assessed himself 1, 2, 3 and 4 hours after dosing.

\section{$P P R$ recording}

The PPR recording procedure has been described elsewhere $(4,8-10)$. The subject lay in a supine position with the eyes closed in a dimly illuminated, sound-proof recording chamber. One dise electrode was placed on the center of the right upper palpebra and the other on the nasal part of the right lower palpebra.

Photic stimuli were applied to the eyes by means of a stroboscope (Nihon Kohden) arranged to operate by a trigger unit fitted to a midget analog-computor (Nihon Kohden, Model ATAC 401). Single flash stimuli were applied with a frequency of one per second from a distance of $10 \mathrm{~cm}$ before the eyes of the subject and the potential changes of the orbicularis oculi muscles thereby evoked were conveyed via an EEG amplifier to the migdet analog-computor which averaged the sum of individual responses. The averaged PPR responses were then magnified and recorded on a $X-Y$ recorder. The analysis time was $250 \mathrm{msec}$. An upward deflection of about $56-58 \mathrm{msec}$ that initially emerged was designated peak $1\left(P_{1}\right)$ and a downward deflection of 73-76 msec approx. which appeared next was 
referred to as peak $2\left(P_{2}\right)$ and both peak latencies were determined, i.e., the $P_{1}$ latency and $P_{2}$ latency.

Assays for blood levels of $1 D-540$ and its principal metabolite

Immediately after drawing samples of blood, sera were separated and stored in a freezer at $-25 \mathrm{C}$. The assays were carried out by gas-chromatography with an electron capture detector.

\section{RESULTS}

\section{$P P R$ changes}

The time-course of changes in both latencies of the PPR is illustrated in Figs. 2 and 3. The peak latencies are expressed in terms of value obtained by subtracting the baseline value (prior to drug administration) from the value at a given time after drug administration.

$P_{1}$ latency was prolonged by $1.5 \mathrm{msec}$ at 30 minutes after an oral dose of ID-540. This prolongation increased thereafter to reach a peak level of $3.0 \mathrm{msec}$ at 150 minutes after drug administration, subsequently with a gradual recovery.

$P_{2}$ latency was prolonged by 2 msec at 30 minutes after an oral dose and the prolongation increased progressively to reach a peak level of $3.8 \mathrm{msec}$ at 120 minutes and $3.6 \mathrm{msec}$ at 150 minutes: thus a maximum prolongation of $P_{2}$ latency was observed between 120 and 150 minutes after administration. A gradual restoration to the initial level followed.

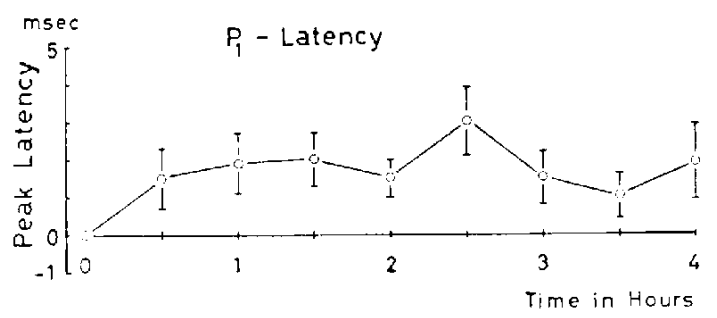

FIG. 2. Effect of ID-540 on the peak 1 latency $\left(P_{1}\right.$ latency). $P_{1}$ latency was prolonged after administration of ID-5.40 as compared with that before the drug and reached a peak at 2.5 hours after dosing.

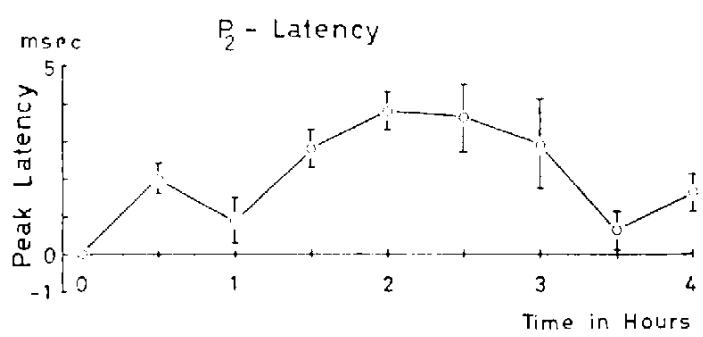

Fig. 3. Effect of ID-540 on the peak 2 latency ( $\mathbf{P}_{2}$ latency). $P_{2}$ latency was prolonged after administration of ID-540 as compared with that before the drug and reached a peak at $2-2.5$ hours after dosing. 

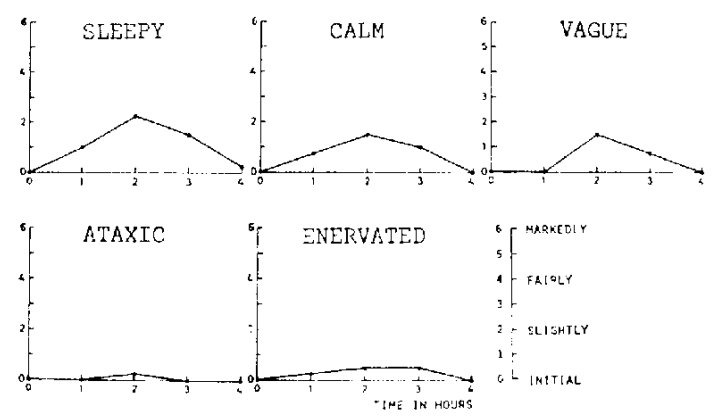

Fig. 4. Effect of ID-540 administration on the self-assessments. Self-assessments of subjective symptoms were made by rating on a seren point $(0$ b) seate and expressed as average scores for individual symptoms in the four subjects.

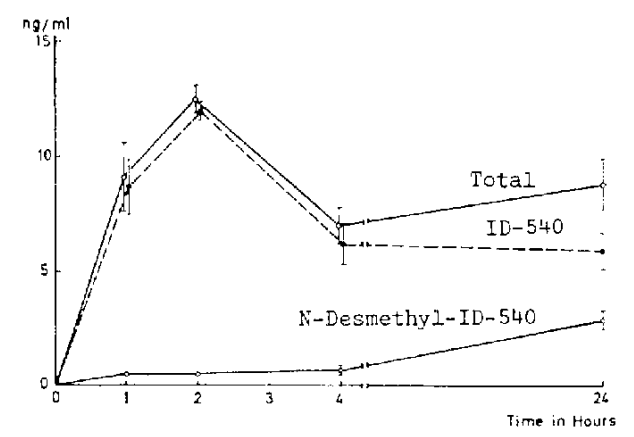

FIG. 5. Serum concentrations of ID-540 and its N-demethylated metabolite, $\mathrm{N}$-desmethyl-ID-540, in man. Serum level of ID-540 reached a peak 2 hours after dosing and subsequently fell rapidly, while that of N-desmethyl-ID-540 displayed no significant alteration during the first 4 hours after an oral dose but increased at 24 hours. Fach value is shown as a mean :- s.c.m..

\section{Changes in subjective symptoms}

Self-assessments made by a seven point (0-6) scale are shown in Fig. 4. Sleepincss, calmness of the mind (tranquility) and vigueness were reported. Incidences and degree of ataxia and weakness were few. All these effects were reportedly strongest at 2 hours ifter an oral dose.

\section{Serum levels of ID-540 and N-desmethyl-ID-540}

The mean concentration of ID-540 exhibited a fairly rapid rise $(8.7 \mathrm{ng} / \mathrm{ml}$ at 1 hour after administration) and reached a peak level of $12.0 \mathrm{ng} / \mathrm{ml}$ at 2 hours as shown in Fig. 5. Subsequently, the level of ID-540 fell rapidly to $6.2 \mathrm{ng} / \mathrm{ml}$ at 4 hours and then decreased gradually.

In contrast, the serum level of N-desmethyl-ID-540, displayed no significant alteration during the first 4 hours after an oral dose but increased at 24 hours. 


\section{DISCUSSION}

Our previous studies demonstrated the usefulness of the PPR test as an effective measure for determining the clinical effects of anxiolytic agents $(4,8-11)$.

ID-540, administered orally in a dose of $0.5 \mathrm{mg}$ prolonged both latencies of the PPR which were maximal approximately 2 to 2.5 hours after ingestion.

In a previous study (9) where a double-blind method was used in a study of male university students, almost the same ages as the volunteers in the present study, no significant changes in the length of $P_{1}$ latency were observed after administration of placebo. This was in contrast to a maximal increase in average $P_{22}$ latency of $2.7 \mathrm{msec}$ at 3 hours after an oral dose of $30 \mathrm{mg}$ flurazepam and that of $2.5 \mathrm{msec}$ at 4 hours after an oral dose of $10 \mathrm{mg}$ nitrazepam.

As to the $\mathrm{P}_{2}$ latency, virtually no change was noted after ingestion of the placebo whereas with flurazepam, a $2.8 \mathrm{msec}$ prolongation was noted at 3 hours after an oral dose of 30 mg. Nitrazepam also prolonged the $P_{2}$ latency by $3.8 \mathrm{msec}$ at 4 hours after an oral dose of $10 \mathrm{mg}$.

When compared in terms of the degree of prolongation of both latencies produced by flurazepam and nitrazepam, the data obtained in the present investigation suggest that ID540 in a dose of $0.5 \mathrm{mg}$ is equipotent to $30 \mathrm{mg}$ of flurazepam or $10 \mathrm{mg}$ of nitrazepam, with the maximum prolongation occurring faster than with the latter two drugs.

As for relationship between subjective assessments and the PPR, the above described PPR changes were noted to coincide well with the incidence of sleepiness as described earlier $(8,9)$.

Changes of the PPR and subjective assessments after administration of ID-540 were in good parallel with the time-course of serum concentration of ID-540 but not of N-desmethyl-ID-540.

These three parameters, i.e., the PPR latencies, subjective assessments and serum concentration of ID-540 presented a striking resemblance in the time-course of changes. This fact may further support our view of predictability of clinical effectiveness of anxiolytic agents by way of evaluation with the PPR test $(8,9)$, though the present investigation was neither a comparative controlled study nor on a double-blind design and in addition, the physiological significance of PPR is not well known.

The PPR has several advantages in that it represents a physiological index for the effects of psychotropic drugs and enables quantification of the responses and determination of equivalent doses and time of maximal effects of drugs.

Acknowledgenents: Gratitutde is due to the technical staff of the Pharmaceutical Division, Sumitomo Chemical Industries for collaboration in assays of ID-540 and Ndesmethyl-1D-540 and to the Company for the generous supply of ID-540. The expert technical assistance of Miss K. Fujiyoshi is also gratefully acknowledged.

\section{REFERENCES}

1) Asami, Y., Otsuka, M., Hirohashi, T., Inaba, S. and Yamamoio, H.: Arzheim.-Forsch. 24, 
1564 (1974)

2) InANaga, K., Yamamoto, Y. ANd Ishikawa, K. Folia psychiat. neurol. Japon. 25, 51 (1971)

3) ITIL, T.M.: Psychopharmacology, Sexual Disorders and Drug Abuse, Edited by Ban, T.A.,

Boissier, J.R., Gessa, G.J., Hfimann, H., Hollisier, L., Lehmann, H.E., Munkvad, I., Steinderg, H., Sulser, F., Sundwall, A. and Vinar̆, O., p. 13, North-Holland Publishing Co., Amsterdam (1973)

4) Kotori, M.: Psychiat. Neurol. Japan. 73, 704 (1971) (in Japanese)

5) Mirira, T.: J. Japan. Stomatol. Soc. 20, 52 (1971) (in Japanese)

6) TANAKA, M. : Psychopharmacology, Theory and Praxis, Edited by InANaGA, K. AND KokeTsu, K., p. 53, Ishiyaku Publishing Co., Tokyo (1973) (in Japanese)

7) Tanaka, M. : Psychopharmacology, Theory and Praxis, Edited by Inanaga, K. And Koretsu, K., p. 111, Ishiyaku Publishing Co., Tokyo (1973) (in Japanese)

8) Tanaka, M., Isozaki, H., Hiral, T. and Inanaga, K.: Rinsho to Kenkyi 51, 511 (1974) (in Japanese)

9) Taxaka, M., Hirai, T., Inanaga, K. and Isozakl, H.: Clin. Psychiat. 16, 193 (1974) (in Japanese)

10) Tavaka, M., Sato, J., Isuzaki, H. and Inanaga, K.: Japan. J. EEG. EMG. 2, 281 (1974) (in Japanese) 